International Journal of Critical Indigenous Studies

Volume 11, Number 1, 2018

\title{
Psychology without culture is almost dead: A case of Aboriginal and Torres Strait Islander children in Australian out-of-home care
}

Authors

Mohajer Abbass Hameed

Shaun Coade

\section{About the authors}

Mohajer has extensive cross-cultural experience as a migrant individual speaking a number of languages. Mohajer holds a master of psychoanalysis and PhD in developmental psychopathology, with an emphasis on quantitative methodologies. He has worked as a senior clinician providing assessment and psychotheraputic interventions with families and children involved with Victorian child protection authorities. Mohajer has also worked as a research and evaluation team leader within a child and family service organisation, and currently is a research fellow within the University of Melbourne Department of General Practice, Safer Families Centre of Research Excellence. Contact him by email at mohajer.hameed@unimelb.edu.au.

Shaun is a Windajeri person from the Monaro Country. Shaun has a broad-ranging background, working initially as a community psychiatric nurse, followed by policy and program development, management and training roles in both mainstream and Aboriginal community organisations over 20 years. Shaun serves on many boards and committees. These include the Committee of Management for Education and Training of Aboriginal Health Workers in Victoria, the Committee for Oversight of Research Studies for the Australian Institute of Family Studies, and the Board of Directors for the Aboriginal and Torres Strait Islanders Healing Foundation. Shaun was instrumental in the development of the first Indigenous family therapy curriculum with La Trobe University-The Bouverie Centre. Shaun also developed the "Yarning Up on Trauma" training program, which is delivered to organisations working with Indigenous families across Australia, and co-authored the publication linked to this training. Contact him by email at scoade@berrystreet.org.au.

\section{Disclaimer on publication}

Authors' affiliations are provided for identification and correspondence purposes only and are not intended to convey or imply concurrence with, or support for, the positions, opinions or viewpoints expressed by the authors. Responsibility for the information and views set out in this paper lies entirely with the authors

Except where otherwise noted, content in this journal is licensed under Creative Commons Attribution 4.0 International Licence. As an open access journal, articles are free to use with proper attribution. ISSN 1837-0144

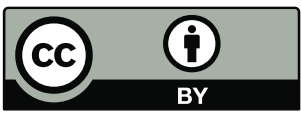




\begin{abstract}
From its inception as a unique discipline, the broad field of psychology has made substantial advances and has contributed to innovative practices in the care of individuals presenting with mental distress within Western Euro-American societies and cultures. The aim of this brief article is to provide a constructive critical analysis of the key limitations, knowledge shortfalls, ineffective assessment approaches and treatment modalities of "mainstream" psychology in addressing the psychological needs of children affiliating with the Aboriginal and Torres Strait Islander culture in Australian out-of-home care. This article selectively draws from an in-depth analysis of the research literature and argues that in its current state, psychology without consideration of Indigenous culture has failed to satisfactorily improve psychological services and outcomes for these children and their families; in other words, psychology without culture is almost dead. This brief article raises various questions for future psychological research within this field and proposes feasible alternatives to these complex issues, supported by successful examples from the child abuse and neglect domain within the child welfare systems in Australia. It concludes with key recommendations for future appropriate inclusive psychological research, with the ultimate goal of strengthening culturally endorsed "healing" practices, service delivery and policies.
\end{abstract}

\title{
Keywords
}

Aboriginal and Torres Strait Islander families and children, Australian out-of-home care, psychology, culture 


\section{Introduction}

In terms of Aboriginal and Torres Strait Islander children and families, Australian psychology has a Black history (Garvey, Dudgeon and Kearins 2000). One of the many negative impacts of psychology "has been evident through an emphasis on a deficits model, intervening through mainstream assimilation approaches, and the provision of assumed expertise ... children were deemed by authorities to be neglected, abused or abandoned or would benefit from assimilation were forcibly removed from their families and communities" (Rickwood, Dudgeon \& Gridley 2010,18). A reflective critical analysis of the past legalised justification of these inhumane practices (collectively termed as Australia's stolen generations, cultural genocide) strengthens the argument that this may have been partially related to Western psychological theories and developments that "have been erroneously labelled universal" (Greenfield 2000, 233).

Heinrich, Heine and Norenzayan (2010) provide a compelling argument for the apparent bias in Western psychology to study human behaviour using "WEIRD" (Western, educated, industrialised, rich, and democratic) samples, yet generalise to the entire human population and global community. Similarly, Arnett (2008) puts forward a strong thesis criticising and questioning the external validity of psychological findings derived from a particular narrow sample bounded by Western culture, context and historical time that overtly assume the universality of the findings; he draws attention to the absence and neglected $95 \%$ of the global human population in major psychological studies. So, what is this thing called psychology? In other words is this "just another White-ology" that assumes universal expertise in human behaviour, which in the past has had a negative role in the "marginalisation, oppression and dispossession" of Aboriginal and Torres Strait Islander communities and peoples (Ranzijn et al. 2007, 22)?

Despite various theoretical discussions, debates and critiques addressing the aforementioned question (Aho 2007; Bode 1922; Bushnan 1859; Holzkamp 1992; PeñaGuzmán 2016; Piaget 1978), there is general consensus that psychology is the science of human behaviour and mental processes (Carlson et al. 2013; Colman 2016). Psychology as both a science (experimental/empirical) and a humanistic practice (clinical/helping) originated and developed in Western Euro-American societies and cultures (Lawson, Graham \& Baker 2007; Louw 2002; Piaget, Fraisse \& Reuchlin 2014). However, if it claims to objectively study human behaviour in general, then why has this Westernised psychology ignored the substantial contributions and understanding of human behaviour derived from some of the earliest and largest societies and cultures of the world? For example, Western psychology has failed to consider the insights, teachings, philosophies, knowledge and understanding of human behaviour and mental processes from some of the most complex societies of the world, such as those of Africa, the Arab nations, China, India, Persia and the Indigenous people around the world (Berry 2013, 2015; Lawson et al. 2007). Yet, critiques show explicit evidence that this Westernised version of psychology is imposed upon the rest of the world (Allwood \& Berry 2006; Bandawe 2005; Timimi 2014), despite the non-fit and lack of relevance in addressing key psychological and social issues facing these societies, cultures and countries. In other words, "psychology at present is largely culture-bound and culture-blind” (Berry 2013, 57; 2015).

This constructively critical brief article draws upon the above-mentioned debates and arguments to appraise the limitations, knowledge shortfalls, ineffective assessment approaches and treatment modalities of the mainstream version of psychology in addressing the psychological needs of Aboriginal and Torres Strait Islander children in Australian out-of-home care. More specifically, this article draws on an in-depth analysis of 
the research literature and argues that in its current state, the Western version of psychology without cultural consideration has almost reached a dead end in relation to working with Aboriginal and Torres Strait Islander children in Australian out-of-home care. While Aboriginal people and Torres Strait Islanders have "very distinctive cultures, but they are linked by their histories and politics" (Tilbury 2009, p. 1), this article argues that the majority of the research methodologies and treatment protocols used by mainstream psychology are inconsistent with both Aboriginal and Torres Strait Islander cultural values and health concepts, and hence have failed to improve psychological services and outcomes for Aboriginal and Torres Strait Islander families and children. This article poses essential questions for future psychological research, proposes feasible alternatives and remedies to these problems, and presents successful examples from the child abuse and neglect domain within the child welfare systems in Australia. Finally, it provides key recommendations for future appropriate and inclusive psychological research, with the ultimate goal of improving culturally endorsed healing practices, service delivery and policies within the Australian out-of-home care system.

\section{Psychological research with children in out-of-home care}

History has documented a range of "inappropriate, unacceptable, devious and degrading research methodologies" used on Aboriginal and Torres Strait Islander peoples (Williams \& Stewart 1992, 4). In reaction to the history of abuse by researchers, a set of guidelines has been developed by a number of organisations to ensure the conduct of ethical research and the appropriateness of study methods used with Aboriginal and Torres Strait Islander communities and peoples (Gorman \& Toombs 2009). These have been extensively detailed and documented elsewhere (Australian Institute of Aboriginal and Torres Straight Islander Studies [AIATSIS] 2013; Eades \& Read 1999; Henderson et al. 2002; Humphery 2001). In addition, key concepts, such as ethical and effective practices, appropriate research methodology, Aboriginal and Torres Strait Islander ownership and control of research and evaluation activities, authentic community involvement and engagement have also been thoroughly discussed elsewhere (Day, Nakata \& Miller 2016; Healey \& Tagak 2014; Humphery 2001).

Specifically, in terms of children in out-of-home care, a focused selective review of the Australian-based and international psychological research literature indicates that overall these research endeavours fall within the broad domains of: (a) description and characteristics of maltreatment; (b) the aetiology and models of causation; (c) the impact of abuse and neglect, along with the child's pathways in care; (d) care system responses and related issues; and (e) psychological treatment and service development, implementation and evaluation. However, the majority of these psychological research endeavours are based upon Western values and scientific paradigms and not Aboriginal and Torres Strait Islander concepts, theories and knowledge. Further, within Australia, there is a limited evidence base for issues related to Aboriginal and Torres Strait Islander children in out-of-home care, and significant research gaps exist (Bromfield et al. 2005; Bromfield \& Osborn 2007; Cashmore \& Ainsworth 2004). Hence, the question remains as to how valid it is to generalise psychological research findings and in many cases impose "scientific and evidence-based psychological practices" upon Aboriginal and Torres Strait Islander children and families. This parallels the argument that "there is relatively little scope for international research to inform direction in this area due to the unique cultural needs of Aboriginal and Torres Strait Islander children" (Bromfield et al. 2005, 25).

For example, the study of high-risk behaviours and risk estimation models is a common psychological research domain. Psychological research within the field of child abuse and 
neglect has been highly influential in elucidating the possible biopsychosocial mechanisms underlying the association between past traumatic experiences (including risk factors within a child's family and social networks) and current mental and physical health outcomes (e.g. high-risk behaviours; Nemeroff 2016; Norman et al. 2012). Arguably, a significant contribution to knowledge in this domain includes appropriate research designed to ascertain and identify the sociocultural context, including situational and environmental variables and/or processes that may ameliorate or provoke such high-risk behaviours or dysfunction. For example, it is unequivocal that the tragic event of child sexual abuse significantly increases the risk of teen sexual risk behaviours, including sexual exploitation (Dowdell et al. 2009; Negriff, Schneiderman \& Trickett 2015; Noll \& Shenk 2013). However, broadening this discussion, Gill critically draws on psychology, media and cultural studies to examine contemporary debates about the increasing trend towards the sexualisation of cultures and the implications and possible impacts (if any) on children's self-esteem, educational attainment and sexual behaviours; yet "this remains the 'black box' ... a curious absence for psychology” $(2012,488)$.

The argument is not about appraising these claims and speculations, nor what is culture, nor to what extent culture influences behaviour and vice versa. Instead, we argue that for Aboriginal and Torres Strait Islander children in Australian out-of-home care, explaining current high-risk behaviours merely in relation to the child's past traumatic experiences is too simplistic as it does not account for historical and current circumstances, or the broader socio-economic and cultural factors that may contribute to and/or elicit these highrisk behaviours. Australian psychological research into out-of-home care is likely to considerably add to the evidence base by examining both distal and proximal variables that are hypothetically associated with high-risk behaviours. These may include, but are not limited to, areas of research such as peer influence within residential care units, social networks, sensation-seeking and adolescent development, placement changes, Aboriginal and Torres Strait Islander children placed with non-Aboriginal and Torres Strait Islander carers, sibling separation, care system responses to and management of high-risk behaviours, and carer/staff cultural competency. These are among the many significant areas that warrant further appropriate research.

In addition, it is justified to question why there is an increasing trend for Aboriginal and Torres Strait Islander children to be removed from their original families and communities. What are the historical and current contributory factors that have led to this unfortunate situation? A comprehensive rigorous trend analysis in reports of child maltreatment in the Northern Territory (Australia) from 1999 to 2010 found "considerable increases in both notifications and substantiated cases of child maltreatment, most prominently among Aboriginal children" (Guthridge et al. 2012, 637). Despite the possible explanations for this increasing trend (e.g. surveillance systems, mandatory reporting obligations, improved service access, changes in policy and a shift in public attitude; Guthridge et al. 2012), this calls for serious consideration of the factors that contribute to, and foster, this ongoing increase in the reported incidence of child maltreatment and subsequent removal of children from their families. The recent Australian Institute of Health and Welfare (2017) report indicates that the national rate of Aboriginal and Torres Strait Islander children in out-of-home care is almost ten times the rate for non-Aboriginal and Torres Strait Islander children. These alarming figures call for urgent appropriate research and culturally endorsed solutions, practice models and service delivery.

In the land that was named Australia, Aboriginal and Torres Strait Islander overrepresentation in child protection services is well documented and reflects a set of complex factors (Tilbury 2009) rooted in a pervasive history of discrimination and 
colonisation, dislocation, and the stolen generation and poverty (Raman et al. 2017; Valentine \& Gray 2006), yet a psychological explanation is unclear. In other words, has Australian-based psychological research sufficiently examined the underlying factors leading to this dramatic situation? Further, within Australia, have social and community research psychologists adequately studied the social and community-based responses that address poverty, alcohol/other drug misuse, family violence, inadequate housing and other factors that may drive the over-representation of Aboriginal and Torres Strait Islander children in out-of-home care? For example, how logical is it to expect an unemployed single mother coping with stressful life circumstances through the use of alcohol and other drugs to combat poverty and fix poor housing situations "without substantial and meaningful social aid and advocacy" (Blackstock \& Trocmé 2005, 29). Have experimental psychologists sufficiently examined the interrelationship between child, family and community-based resilience factors and Aboriginal and Torres Strait Islander child maltreatment rates? Moreover, have child and adolescent research psychologists adequately investigated resilience factors in young people, as well as how to best support families and strengthen positive parenting styles? Next, have clinical research psychologists adequately ascertained the seeming "psychological paralysis" that may prevent Aboriginal and Torres Strait Islander communities and peoples to break the intergenerational cycle of trauma? Further, when tapping into the underlying factors and variables, of equal importance is the urgent need for appropriate research that ascertains (at both state and national level) the broader systemic factors that may have contributed to, and led to, increases in the family violence incidents, abusive behaviours and health risk factors that are predictive of child abuse and neglect. These points warrant serious reflection and consideration. They are few of the many essential questions that are yet to be adequately answered that may contribute towards the ultimate goal of reducing (and ideally eliminating) this appalling and tragic increasing over-representation rate in Australia.

Despite the complexities in practice and implementation barriers, almost 20 years have passed since the Bringing Them Home Report (Wilkie 1997) and the enactment of some innovative legislation and policies, such as the Aboriginal and Torres Strait Islander Child Placement Principle. When analysing such initiatives, the essential question remain as to what extent has the goal of keeping them at home with their families and extended kinship, or if this is not possible then with Aboriginal and Torres Strait Islander carers within their communities, been achieved? Further, nearly 13 years ago, Bromfield and colleagues (2005) argued that there is an urgent need for appropriate research that compares children's psychosocial outcomes, including cultural and spiritual dimensions, for "those who are placed in accordance with the Aboriginal and Torres Strait Islander Child Placement Principle (with kinship and non-related Aboriginal and Torres Strait Islander placements) and non-Indigenous placements" (Bromfield et al. 2005, 25). This raises the question of "Are we there yet?" in addressing the wellbeing of Aboriginal and Torres Strait Islander children in out-of-home care (Raman, Reynolds \& Khan 2011), and in terms of "taking culture seriously" for these children (Raman et al. 2017).

Specifically, in terms of research, the Maori writer Linda Tuhiwai Smith (2013) states that "research is probably one of the dirtiest words in the Indigenous world's vocabulary" (1), and strongly calls for the "decolonisation" of research methodologies, as well as a new agenda for Indigenous research. While this is a desirable aim, we argue that mainstream psychological research methods (when utilised appropriately) are at least to a certain extent potentially compatible with Aboriginal and Torres Strait Islander culture and heritage (Gorman \& Toombs 2009). For example, narrative research (Wilson 2007), conversational methods (Kovach 2010), participatory action research or community-based participatory 
research approaches (Fong, Braun \& Tsark 2003; Tsey et al. 2002) have been shown to be received well by Aboriginal and Torres Strait Islander communities and peoples. However, while these research approaches are promising, non-Aboriginal and Torres Strait Islander researchers may still hold the "Western scientific worldview ... and research epistemologies ... above others" (Healey \& Tagak 2014, 1). Alternatively, inclusive research and working collaboratively with Aboriginal and Torres Strait Islander communities and peoples offers opportunities for innovation and culturally appropriate research that is likely to secure both researchers' interests (e.g. knowledge generation, career progress) and the best interests of Aboriginal and Torres Strait Islander communities and peoples. In other words, the "call for Aboriginal control of research activities" needs to be taken seriously (Humphery 2001, 198).

Any psychological research method used needs to be culturally sensitive and consider Aboriginal and Torres Strait Islander ways of knowing and developing knowledge. One of the successful examples of a research method and assessment strategy used with Aboriginal and Torres Strait Islander communities is "Yarning about Yarning" in Western Australia (Bessarab \& Ng'andu 2010). Although this research was not about children in out-of-home care, the different approaches such as social, research, collaborative and therapeutic yarning are equally applicable with Aboriginal and Torres Strait Islander families and children in out-of-home care. Generally, these approaches align with Aboriginal and Torres Strait Islander communities and peoples' unique and rich oral history and "transmitting knowledge from generation to generation through stories" (Gorman \& Toombs 2009, 7), yet this needs to occur within the broad framework of strong "commitment to principles of mutual respect, inclusion and shared responsibility" (Rickwood et al. 2010, 22).

\section{Psychological assessments and outcome measures}

The importance of standardised psychological assessments and outcome measures within the domain of child abuse and neglect has been highlighted and critically evaluated elsewhere (Hameed 2018). Multiple research and data collection methods have been evaluated in relation to their applicability, relevance and limitations for Aboriginal and Torres Strait Islander peoples (Braun et al. 2013). However, professionals working with Aboriginal and Torres Strait Islander families and their children frequently express the concern that these Western psychological assessments do not always benefit the child and may even inflict harm (Gould 2008; Pearce \& Williams 2013). On the basis of such arguments, supporting research evidence, as well as professional experience in this field, we argue that the use of standardised psychological assessments with Aboriginal and Torres Strait Islander children in out-of-home care may potentially result in misdiagnosis and erroneous interpretation that may fail to inform culturally appropriate interventions and treatment plans.

Further, despite substantial advances in the field of psychiatry, psychological practice and welfare service delivery, Timimi (2014) draws upon numerous literature reviews and research findings and critically questions the clinical usefulness of diagnostic-based medical models (e.g. the International Classification of Diseases, Tenth Revision [ICD-10], World Health Organization 1992; Diagnostic and Statistical Manual of Mental Disorders, Fifth Edition [DSM-5], American Psychiatric Association 2013) within the general population. In reference to this argument, it is also plausible to criticise their utility within a highly complex system of out-of-home care in which children often present with multiple "clinical" presentations. Hence, one may argue that whether "formal psychiatric diagnostic systems like ICD and DSM should be abolished", as suggested by Timimi $(2014,213)$, 
warrants further investigation. These arguments generally align with the collective national and international efforts that call for the "decolonisation" of research methods and assessments and the development of culturally sensitive approaches to assessment and outcome measures within various domains, including child abuse and neglect (Braun et al. 2013; Kovach 2010; Smith 2013; Stanley, Tomison \& Pocock 2003).

For example, drawing on the educational psychology literature, it is reported that the overrepresentation of Aboriginal and Torres Strait Islander students in special education in Australia, as well as Indigenous students worldwide in general, may constitute a new form of systemic racial discrimination (de Plevitz 2006; Santoro et al. 2011). This sensitive debate largely alludes to the cultural biases inherent in the assessment strategies and diagnostic criteria that have been demonstrated as unreliable and invalid for Aboriginal and Torres Strait Islander children (Pearce \& Williams 2013). Children in out-of-home care in general, and Aboriginal and Torres Strait Islander children in particular, who have experienced various types of abuse and neglect (including historical intergenerational trauma with an overlay of both genetic and environmental influences and factors) present with a range of developmental and psychosocial concerns, including educational issues manifested as speech and language difficulties. One of the successful examples of the development of a culturally sensitive and appropriate tool for this highly vulnerable population includes the "Small Talk Tool" (Frederico et al. 2017). A key lesson learned from reviewing this study is that "the tool's design was culturally informed in terms of Australian Aboriginal children in consultation with a lead Aboriginal Community Controlled Organisation (VACCA) and an Aboriginal consultant within Take Two" (Frederico et al. 2017,9 ). This principle of collaborative research approach and inclusion ("nothing about us without us") is a key factor contributing towards the development and implementation of culturally appropriate assessment and data collection strategies.

On a broader scale in general, Aboriginal and Torres Strait Islander culture is relational and collectivist in comparison to Western cultures. In collectivist cultures the sense of self (the person) is perceived not as an independent self, but as a self-in relationship and "connected to all aspects of life, community, spirituality, culture and country" (Purdie, Dudgeon \& Walker 2010, 3). Different perspectives on the origin of culture, definitions and the psychological need to create culture in general are described elsewhere (Lehman, Chiu \& Schaller 2004; Triandis, Malpass \& Davidson 1973). The key message is that in general, the Aboriginal and Torres Strait Islander concepts of self and culture have significant implications for the individualistic focus of the major mainstream psychological assessments and outcome measures. Further, terms such as social, emotional and spiritual wellbeing (SEWB) are generally preferred by Aboriginal and Torres Strait Islander peoples over terms such as mental disorders, illness, psychopathology, deficits, dysfunction and disease. The construct of SEWB reflects a holistic philosophy and multidimensional concept of health that "views the self as inseperable from, and embedded within, family and community ... shaped by connections to body, mind and emotions, family and kinship, community, culture, land and spirtuality" (Gee et al. 2014, 58). Arguably, the science of psychological assessment has a longstanding, successful history of scale development and psychometrics (Rust \& Golombok 2014), yet there is still a lack of suitable assessment tools that adequately measure SEWB in Aboriginal and Torres Strait Islander children and young individuals in the out-of-home care context. Further, Aboriginal and Torres Strait Islander communities and peoples are not homogenous, and this adds to the assessment-related challenges that face psychometricians if such attempts are to be progressed in Australia. 
A small number of culturally validated measures (e.g. the Here and Now Aboriginal Assessment, Westerman Aboriginal Symptom Checklist, Strong Souls Inventory, Negative Life Events Scale) have been developed, implemented and evaluated in relation to assessing various domains of SEWB (Janca et al. 2015; Kowal, Gunthorpe \& Bailie 2007; Newton et al. 2015) and how they change over time as a result of the very few promising programs and services within Australia (Day \& Francisco 2013; Day et al. 2016; Skerrett et al. 2017). However, while beneficial to Aboriginal and Torres Strait Islander communities and peoples, their applicability, feasibility, reliability and validity within the context of out-ofhome care warrants further investigation. Critical assessment-related questions facing the out-of-home care sector are how, and to what extent, the commonly used Western psychological assessments and outcome measures inform and support the strengthening of SEWB for Aboriginal and Torres Strait Islander families and children in care? Are the currently commonly used psychological outcome measures within child welfare services designed to measure and strengthen SEWB and, in particular, spirituality and connection to land, country, culture and extended kinship? To what extent do the commonly utilised psychological assessments inform and direct the cultural support planning for Aboriginal and Torres Strait Islander children in Australian out-of-home care? One may argue that the commonly used psychological tools are not designed to measure the above constructs, leading to the question of what is available? It is very clear that there is an urgent need for appropriate psychological research in this domain; in particular, in relation to cultural support and connection to land, country, culture and community. This is paramount, since SEWB is influenced by a wide range of adverse experiences such as discrimination, racism, grief and loss, child removals by care and protection orders, unresolved trauma, economic and social disadvantage, incarceration, family violence, substance use, physical health problems and cultural disconnection (Zubrick et al. 2014; Gee et al. 2014).

A recent Victoria-based exploratory research study with staff from mainstream and Aboriginal and Torres Strait Islander child and family welfare agencies identified various shortcomings of the current care systems in addressing the complexities of cultural support planning for Aboriginal and Torres Strait Islander children in, and leaving, out-ofhome care (Baidawi, Mendes \& Saunders 2017). The study adopted an inductive content analysis approach and found that strategies for improved outcomes include "facilitating better relationships between agencies, promoting opportunities for ongoing cultural training for staff in mainstream agencies and improving the resourcing of Aboriginal community controlled organisations to deliver planning and to support cultural connections" (Baidawi et al. 2017, 731). Further, reflection on the study's findings and, in particular, the theme of some Aboriginal and Torres Strait Islander children's "cultural confusion, denial and uncertainty" is highly concerning, given that drivers for such an attitude may include "fear of racism and cultural shame ... limiting their opportunities for employment and things like that as well-which is not unrealistic" (Baidawi et al. 2017, 735). Nevertheless, the complexities and barriers of developing and implementing cultural support plans, combined with the administration of Western psychological assessments that presumably are perceived as having no meaning to Aboriginal and Torres Strait Islander families and their children in care, consequently fail to inform culturally appropriate services, psychological treatments and therapeutic models.

\section{Psychological treatments and therapeutics}

Irrespective of divergent aetiological viewpoints and "culture-specific" versus "universal" contributory risk factors across all racial and ethnic groups, child abuse and neglect appear to occur in epidemic numbers around the world, with devastating lifelong consequences (Hoft \& Haddad 2017; Jackson \& Gibbs 2016; Norman et al. 2012; Plener 
et al. 2017; Stoltenborgh et al. 2011). In some cases, child protection practices necessitate the involuntary removal of a child from their original family. These practices occur with the intention to apply the "best interests" principle to decisions about the child, including child health and wellbeing during out-of-home care (Jackson 2012). Evidently there are controversies, challenges and difficulties in balancing the child's best interests, child-family views and family preservation (Archard \& Skivenes 2009), and the child's right to participate in decisions made about them (de Fina 2010; Lundy 2007). The best interests of Aboriginal and Torres Strait Islander communities and peoples (Lynch 2001) must also be considered, as well as whether these practices are demanding Aboriginal and Torres Strait Islander families "conform to a dominant mother or family type" (Cripps 2012, 26). Further, in a thoughtful analysis, Valentine and Gray (2006) stated that "the separation of Aboriginal children from their families through child protection and the juvenile justice systems are "band-aid solutions" that avoid larger systemic issues" (14). However, despite the aforementioned debates and controversies, all children, including those affiliating with the Aboriginal and Torres Strait Islander heritage, who are adversely impacted by abuse and neglect urgently need support and help. In other words, they need appropriate psychological treatments and therapies. In this context, appropriateness implies that in the mix of many practices, such as placement of Aboriginal and Torres Strait Islander child into non-Aboriginal and Torres Strait Islander families residing outside their community, any form of psychotherapeutics with no cultural consideration may add to unconscious manifestations of latent assimilationist practices. It is here where psychology without culture is almost dead; to this might be added, potentially detrimental and harmful.

The strong emphasis on the development and implementation of cost-effective evidencebased interventions for children in Australian out-of-home care is a justifiable and desirable goal (Hameed 2018). What is the best and most effective way to make the greatest impact in defeating child maltreatment and preserving family unity? What are the facilitators and barriers to strengthening parental bonding and positive "family" attachment styles? These are among many of the complex questions to answer, yet critically, it is of equal importance to urgently ascertain what works with and for Aboriginal and Torres Strait Islander families and children in Australian out-of-home care. However, a key point is that a Western scientifically endorsed effective treatment modality is not necessarily "deadly" for Aboriginal and Torres Strait Islander families and children in out-of-home care. These points warrant further appropriate investigation.

Nevertheless, leading psychological treatments and therapeutics such as trauma-informed cognitive behavioural therapy (Cohen \& Mannarino, 2015), solution-focused brief therapy (Cepukiene \& Pakrosnis 2011), foster carer interventions and support (Dorsey et al. 2008), multi-systemic therapy (Swenson et al. 2010), eye movement desensitisation and reprocessing (Tufnell 2005), and the neurosequential model of therapeutics (Perry 2009) in the treatment and promotion of recovery in children impacted by "complex developmental trauma" (Cook et al. 2005) are promising. However, their adaptability, applicability, utility and cultural appropriateness with Aboriginal and Torres Strait Islander families and children in Australian out-of-home care warrants further investigation.

Alternatively, in collaboration with Aboriginal and Torres Strait Islander professionals and organisations, an in-depth constructive critical systematic review of the aforementioned treatment modalities in terms of similarities, differences, expected outcomes, mode of delivery, duration and reported effectiveness may facilitate and/or inform the development of local culturally appropriate "healing" practices that may work better for Aboriginal and Torres Strait Islander children in out-of-home care. This would be a key research initiative in the field of child abuse and neglect in Australia. 
Further, a significant foundation of any given psychological treatment modality is the therapeutic alliance/relationship (Ormhaug et al. 2014) and the therapist's characteristics and experiences (Accurso \& Garland 2015). When this relationship is at the centre of any psychological treatment, then arguably a respected Elder and respected persons with strong positive relationships with the Aboriginal and Torres Strait Islander family and child in out-of-home care may contribute to and elicit a greater genuine positive impact than a highly experienced but non-Aboriginal and Torres Strait Islander registered psychologist. This speculation is subject to critical debate and is worth further investigation. This may also parallel the argument that Aboriginal and Torres Strait Islander children may prefer to have an Aboriginal and Torres Strait Islander support worker during their out-of-home care journey, yet Australian-based research is limited to supporting or negating such arguments. Realistically, there are not enough Aboriginal and Torres Strait Islander workers in the field of child abuse and neglect, nor sufficient resources available to strengthen and further "develop and fund Aboriginal child welfare training programs for Aboriginal workers" (Valentine \& Gray 2006, 17). Hence, one of the many feasible alternatives would be to build upon established approaches in psychology through respectful collaboration and partnerships between Aboriginal and Torres Strait Islander-led organisations and mainstream services to ensure the provision of culturally sensitive and competent services.

The comprehensive report entitled Supporting the Roadmap for Reform: Evidenceinformed Practice (Moore et al. 2016) utilised a rapid evidence assessment methodology and identified 33 Australian-based programs that met the criteria of efficacy in addressing various facets of child maltreatment. In terms of Aboriginal and Torres Strait Islander populations, only one program, namely "Take Two", was identified and reported to address the needs of Aboriginal and Torres Strait Islander families and children in out-of-home care within Victoria, yet its effectiveness has not been demonstrated "with an RCT evaluation" (Moore et al. 2016, 8). Nevertheless, the beauty of the Take Two as a well-established program is within its relational and holistic approach to healing childhood trauma (Jackson et al. 2009) and with its flexibility to adapt and address children's needs, including cultural diversity, as one size does not fit all (Bamblett et al. 2012).

Further, of equal importance is the issue of Aboriginal and Torres Strait Islander young people leaving care. Consistent with the aforementioned report, it is argued that "their journey to adulthood is both accelerated and compressed" (Stein 2006, 274). A Victorianbased exploratory research project identified key challenges and barriers for cultural connectedness of Aboriginal and Torres Strait Islander care leavers (Mendes, Saunders \& Baidawi 2016). These include systemic matters such as "issues identifying Indigenous status, complex relationship between Indigenous and non-Indigenous services, concerns around inadequate referral pathways to Aboriginal community controlled organisations (ACCOs), and limited funding for Indigenous-specific programs and supports" (Mendes et al. 2016, 7). Nevertheless, in terms of psychological research, it is worth addressing questions such as how do experiences (e.g. stigma) of out-of-home care contribute to and/or shape the person's perception of self-identity, personality traits, connection to land, country, culture, community, family and kinships? Further, what is the impact of perceived racism and discrimination upon the young person's self-esteem and resilience? It appears that the Australian-based psychological literature has not sufficiently addressed these questions within the context of out-of-home care and transition into adulthood. In addition, the implications for those young individuals who either move on, survive, and/or become victims upon leaving out-of-home care (Stein 2006) are not sufficiently studied, nor has longitudinal evaluation of psychological treatments and services adequately ascertained the Aboriginal and Torres Strait Islander child's pathways in care that lead to each one of 
these outcomes, and the implications for adult life. These are among many urgent areas for future appropriate research.

\section{A need for a new approach (Indigenous and global psychology)}

There is absolutely no doubt that there can be no health without mental health (Prince et al. 2007), yet we argue that this ought to be interpreted and conceptualised in reference to the sociocultural framework of any given society or community. Arguably, "culture" is inseparable from "mental health" and together these need to be "integrated into all elements of health and social policy, health-system planning, and health-care delivery" (Prince et al. 2007, 870). For example, while complex multifactorial psychological and social phenomena such as child abuse and youth suicide are global public health concerns, the solutions and interventions designed to prevent and combat such multifaceted issues are conceptualised differently across cultures. Hence, different culturally appropriate possibilities for prevention and early intervention are emerging.

One of the few successful examples of a community-led youth suicide prevention strategy is the Aboriginal and Torres Strait Islander Suicide Prevention Evaluation Project (Dudgeon et al. 2016). The project highlights the importance of Aboriginal and Torres Strait Islander community leadership and cultural framework and proposes a set of culturally relevant recommendations. One of the key messages and lessons learned from reviewing this report is that locally developed, implemented and evaluated assessment tools and prevention and early intervention activities are more culturally appropriate in addressing the needs and issues facing Aboriginal and Torres Strait Islander communities and peoples. This is an Aboriginal and Torres Strait Islander made and owned product that can do better than imposing a culturally non-relevant program, as the latter would risk undermining the existing sociocultural frameworks for dealing with such complex issues.

Similarly, within Australian out-of-home care, participation and ownership of Aboriginal and Torres Strait Islander communities and peoples in the development, implementation and evaluation of appropriate psychological assessment tools and healing/treatment models would ensure and promote Aboriginal and Torres Strait Islander self-determination, resilience and capacity building at individual, community, institutional and societal levels. Any research that is governed and owned by the Aboriginal and Torres Strait Islander communities and peoples is highly likely to be successfully translated into improved practices, inform better polices and strengthen culturally sensitive health systems that directly benefit Aboriginal and Torres Strait Islander families and children. While this "requires considerable input and support from government" (Valentine \& Gray 2006, 18), one of the many substantial gains from such investments would also be towards establishing and fostering an Australian Indigenous psychology.

A move towards Indigenous psychologies in various regions of the world (Allwood \& Berry 2006) and global psychology (Berry 2015) entails the study of specificity and universality respectively. Researchers around the world are attempting to develop psychologies that are locally appropriate to their sociocultural context (specificity). Through comparative methodologies, these research endeavours may also contribute to our understanding of psychological universals, that is, what we all share as members of humanity (universality; Berry 2013). Both Indigenous and global psychology are significant additions to Western psychology. In fact, "the psychology that most of us know and practice (and which is sometimes thought to be universal) is actually just an Indigenous psychology of the West" (Berry 2013, 59). To this might be added, that not surprisingly, it has almost failed to address the psychological needs of Aboriginal and Torres Strait Islander children in 
Australian out-of-home care. Nevertheless, prevention of, and early intervention in, child abuse and neglect remains a universal goal.

This universal achievable goal of prevention and early intervention should unite all child abuse and neglect researchers, practitioners and policymakers around the world in general, and Australia in particular. However, it takes courage to constructively criticise and question the universality of Western psychology and challenge its dominance and assumed universal expertise, as the analyst would risk his or her professional credibility within the dominant academic and clinical stream. John Berry firmly states that "it is a truism that all forms of domination eventually come to an end. Whether they are empires or scientific paradigms, nothing lasts forever" $(2013,60)$. Consequently, the audacity, united voice and collective actions of Aboriginal and Torres Strait Islander psychologists has considerabily contributed to the formation of the Australian Indigenous Psychologists Association in 2008, under the auspices of the Australian Psychological Society. The collective and united work of Aboriginal and Torres Strait Islander psychologists in collaboration with mainstream psychological professionals and services will ensure finding and creating local and culturally endorsed solutions that may work better in preventing and combating child abuse and neglect within Aboriginal and Torres Strait Islander communities and families.

\section{Conclusion}

While Australian psychology has a Black history (Garvey et al. 2000), this brief article has extended the debate with a central argument that psychology without culture is almost dead. The overarching theme of discussion was that in its current state, the mainstream version of psychology has almost failed to satisfactorily improve psychological services and outcomes for Aboriginal and Torres Strait Islander children in Australian out-of-home care. Nevertheless, in the highly sensitive context of child abuse and neglect, there is still hope for discovering culturally endorsed solutions and modalities of healing that work better with and for Aboriginal and Torres Strait Islander families and children. While past Australian psychological research has had a negative impact on Aboriginal and Torres Strait Islander communities and peoples, appropriate present research has the potential to contribute to better health and wellbeing, but only when the "universality mindset" is put aside, along with a strong "commitment to principles of mutual respect, inclusion and shared responsibility in moving forward to a better future" (Rickwood et al. 2010, 22). Simply, when land, country, culture, community, dreamtime and kinship are essential elements of Aboriginal and Torres Strait Islander heritage, then this necessitates the fundamental integration of culture in all research endeavours, practice models and service delivery. Aboriginal and Torres Strait Islander psychologists and professionals have a significant contributory role in the collective efforts to intervene and prevent child abuse and neglect at the very early stages in child development, as well as improving the care system responses to these adverse experiences. The ultimate goal is to protect and promote the rights of the children and young people in Australia, and throughout the rest of the world. 


\section{References}

Australian Institute of Health and Welfare (AlHW). 2017. Australia's welfare 2017 (Australia's welfare series no. 13). Canberra: AlHW.

Accurso, Erin C. and Ann F. Garland. 2015. "Child, caregiver, and therapist perspectives on therapeutic alliance in usual care child psychotherapy." Psychological Assessement 27 (1), 347-352.

Aho, Kevin A. 2007. "Acceleration and time pathologies: The critique of psychology in Heidegger's Beiträge." Time \& Society 16 (1), 25-42.

American Psychiatric Association. 2013. Diagnostic and statistical manual of mental disorders (5th ed). Arlington: American Psychiatric Publishing.

Australian Institute of Aboriginal and Torres Straight Islander Studies (AIATSIS). 2013. Guidelines for Ethical Research in Indigenous Studies. Canberra: AIATSIS.

Allwood, Carl M. and John W. Berry. 2006. "Origins and development of Indigenous psychologies: An international analysis." International Journal of Psychology 41 (4), 243268.

Archard, David W. and Marit Skivenes. 2009. "Balancing a child's best interests and a child's views." International Journal of Children's Rights 17, 1-21.

Arnett, Jeffrey J. 2008. "The neglected 95\%: Why American psychology needs to become less American." American Psychologist 63 (7), 602-614.

Baidawi, Susan, Philip Mendes and Bernadette J. Saunders. 2017. "The complexities of cultural support planning for Indigenous children in and leaving out-of-home care: The views of service providers in Victoria, Australia." Child \& Family Social Work 22 (2), 731 740.

Bamblett, Muriel, Margarita Frederico, Jane Harrison, Annette Jackson and Peter Lewis. 2012. 'Not one size fits all': Understanding the social \& emotional wellbeing of Aboriginal children. Melbourne: La Trobe University.

Bandawe, Chiwoza R. 2005. "Psychology brewed in an African pot: Indigenous philosophies and the quest for relevance." Higher Education Policy 18 (3), 289-300.

Berry, John W. 2013. "Achieving a global psychology." Canadian Psychology 54 (1), 5561.

Berry, John W. 2015. "Global psychology: Implications for cross-cultural research and management." Cross Cultural Management 22 (3), 342-355.

Bessarab, Dawn and Bridget Ng'andu. 2010. "Yarning about yarning as a legitimate method in Indigenous research." International Journal of Critical Indigenous Studies 3 (1), 37-50.

Blackstock, Cindy and Nico Trocmé. 2005. "Community-based child welfare for Aboriginal children: Supporting resilience through structural change." Social Policy Journal of New Zealand (24), 12-33.

Bode, Boyd H. 1922. "What is psychology?" Psychological Review 29 (4), 250-258.

Braun, Kathryn L., Collette V. Browne, Lana Sue Ka'opua, L. S., Bum Jung Kim and Noreen Mokuau. 2013. "Research on indigenous elders: From positivistic to decolonizing methodologies." Gerontologist 54 (1), 117-126. 
Bromfield, Leah, Daryl Higgins, Alexandra Osborn, Stacey Panozzo and Nick Richardson. 2005. Out-of-home care in Australia: Messages from research. Melbourne: Australian Institute of Family Studies.

Bromfield, Leah and Alexandra L. Osborn. 2007. 'Getting the big picture': A synopsis and critique of Australian out-of-home care research (Vol. 26): Melbourne: Australian Institute of Family Studies Melbourne.

Bushnan, J. Stevenson. 1859. "What is psychology?" The British Journal of Psychiatry 6 (31), 39-49.

Carlson, Neil R., Harold L. Miller, Donald S. Heth, John W. Donahoe and G. Neil Martin. 2013. Psychology: Pearson new international edition: The science of behavior. Upper Saddle River: Pearson.

Cashmore, Judy and Frank Ainsworth. 2004. Audit of Australian out-of-home care research. Sydney: Association of Childrens Welfare Agencies.

Cepukiene, Viktorija and Rytis Pakrosni. 2011. "The outcome of solution-focused brief therapy among foster care adolescents: The changes of behavior and perceived somatic and cognitive difficulties." Child Youth Services Review 33 (6), 791-797.

Cohen, Judith A. and Anthony P. Mannarino. 2015. "Trauma-focused cognitive behavior therapy for traumatized children and families." Child and Adolescent Psychiatric Clinics 24 (3), 557-570.

Colman, Andrew. 2016. What is psychology? London and New York: Routledge Taylors \& Francis Group.

Cook, Alexandra, Joseph Spinazzola, Julian Ford, Cheryl Lanktree, Margaret Blaustein, Marylene Cloitre and Bessel Van der Kolk, B. 2005. "Complex trauma in children and adolescents." Psychiatric Annals 35 (5), 390-398.

Cripps, Kyllie. 2012. "Indigenous children's 'best interests' at the crossroads: Citizenship rights, Indigenous mothers and child protection authorities." International Journal of Critical Indigenous Studies 5 (2), 25-35.

Day, Andrew and Ashleen Francisco. 2013. "Social and emotional wellbeing in Indigenous Australians: Identifying promising interventions." Australian and New Zealand Journal of Public Health 37 (4), 350-355.

Day, Andrew, Martin Nakata and Keith Miller. 2016. "Programs to improve the social and emotional wellbeing of Aboriginal and Torres Strait Islander communities." Australian Social Work 69 (3), 373-380.

de Fina, Deborah. 2010. Article 12 of UNCROC and the Participation of Children in Statutory Child Protection Decision-making in Australia.

http://www.childrenscourt.justice.nsw.gov.au/.

de Plevitz, Loretta. 2006. "Special schooling for Indigenous students: A new form of racial discrimination?" The Australian Journal of Indigenous Education 35, 44-53.

Dorsey, Shannon, Elizabeth M. Farmer, Richard P. Barth, Kaylin M. Greene, John Reid and John Landsverk. 2008. "Current status and evidence base of training for foster and treatment foster parents." Child Youth Services Review 30 (12), 1403-1416.

Dowdell, Elizabeth B., Deborah J. Cavanaugh, Ann W. Burgess and Robert A. Prentky. 2009. "Girls in foster care: A vulnerable and high-risk group." MCN The American Journal of Maternal Child Nursing 34 (3), 172-178. 
Dudgeon, Pat, Jill M. Milroy, Tom Calma, Yvonne Luxford, lan Ring, Roz Walker, Adele Cox, Gerry Georgatos and Christopher Holland. 2016. Solutions that work: What the evidence and our people tell us. Aboriginal and Torres Strait Islander Suicide Prevention Evaluation Project Report. Perth: School of Indigenous Studies, University of Western Australia.

Eades, Sandra J. and Anne W. Read. 1999. "The Bibbulung Gnarneep Project: Practical implementation of guidelines on ethics in indigenous health research." The Medical Journal of Australia 170 (9), 433-436.

Fong, Megan, Kathryn L. Braun and JoAnn Umilani Tsark. 2003. "Improving Native Hawaiian health through community-based participatory research." Californian Journal of Health Promotion 1 (1), 136-148.

Frederico, Margarita, Annette L. Jackson, Carly M. Black, Allison Cox and Beverly Joffe. 2017. "Small talk: Identifying communication problems in maltreated children." Child Abuse and Neglect, 75, 139-148.

Gee, Graham, Pat Dudgeon, Clinton Schultz, Amanda Hart and Kerrie Kelly. 2014. "Aboriginal and Torres Strait Islander Social and Emotional Wellbeing." Working Together: Aboriginal and Torres Strait Islander Mental Health and Wellbeing Principles and Practice, edited by Pat Dudgeon, Helen Milroy and Roz Walker (Eds), 55-69. Commonwealth of Australia.

Garvey, Darren, Patricia Dudgeon and Judith Kearins. 2000. "Australian psychology has a black history." Working with Indigenous Australians: A handbook for psychologists, edited by Dudgeon, Patricia, Darren Garvey and Harry Pickett (Eds), 231-247. Perth: Gunada Press.

Gill, Rosalind. 2012. "The sexualisation of culture?" Social and Personality Psychology Compass 6 (7), 483-498.

Gorman, Don and Maree Toombs. 2009. "Matching research methodology with Australian indigenous culture." Aboriginal and Islander Health Worker Journal 33 (3), 4-7.

Gould, Judith. 2008. "Non-standard assessment practices in the evaluation of communication in Australian Aboriginal children." Clinical Linguistics and Phonetics 22 (8), 643-657.

Greenfield, Patricia M. 2000. "Three approaches to the psychology of culture: Where do they come from? Where can they go?" Asian Journal of Social Psychology 3 (3), 223-240.

Guthridge, Steven L., Philip Ryan, John R. Condon, Leah M. Bromfield, John R. Moss and John W. Lynch. 2012. "Trends in reports of child maltreatment in the Northern Territory, 1999-2010." The Medical Journal of Australia 197 (11), 637-641.

Hameed, Mohajer A. 2018. "Challenges and opportunities for innovation in child abuse and neglect research within the child welfare system in Australia." Children Australia 43 (1), 5766.

Healey, Gwen and Andrew Tagak Sr. 2014. "PILIRIQATIGIINNIQ 'Working in a collaborative way for the common good': A perspective on the space where health research methodology and Inuit epistemology come together." International Journal of Critical Indigenous Studies 7 (1), 1-14.

Henderson, Rick, David S. Simmons, Lisa Bourke and Janice Muir. 2002. "Development of guidelines for non-Indigenous people undertaking research among the Indigenous population of north-east Victoria." Medical Journal of Australia 176 (10), 482-485. 
Henrich, Joseph, Steven J. Heine and Ara Noranyazan. 2010. "The weirdest people in the world." Behavioral and Brain Sciences 33 (2-3), 61-135.

Hoft, Mary and Lisa Haddad. 2017. "Screening children for abuse and neglect: A review of the literature." Journal of Forensic Nursing 13 (1), 26-34.

Holzkamp, Klaus. 1992. "On doing psychology critically." Theory \& Psychology 2 (2), 193204.

Humphery, Kim. 2001. "Dirty questions: Indigenous health and 'Western research'." Australian and New Zealand Journal of Public Health 25 (3), 197-202.

Jackson, Annette. 2012. "Applying the 'best interests' principle to decisions about child health in out-of-home care." Developing Practice: The Child, Youth and Family Work Journal 30, 9-14.

Jackson, Annette, Margarita Frederico, Chris Tanti and Carlina Black. 2009. "Exploring outcomes in a therapeutic service response to the emotional and mental health needs of children who have experienced abuse and neglect in Victoria, Australia." Child \& Family Social Work 14 (2), 198-212.

Jackson, Angela and Anita Gibbs. 2016. "New Zealand's Home for Life Policy: Telling children they matter but only for three years." International Journal of Law, Policy and the Family 30 (3), 322-337.

Janca, Aleksandar, Zaza Lyons, Sivasankaran Balaratnasingam, Dora Parfitt, Sophie Davison and Jonathan Laugharne. 2015. "Here and now Aboriginal assessment:

Background, development and preliminary evaluation of a culturally appropriate screening tool." Australasian Psychiatry 23 (3), 287-292.

Kovach, Margaret. 2010. "Conversation method in Indigenous research." First Peoples Child \& Family Review 5 (1), 40-48.

Kowal, Emma, Wendy Gunthorpe and Ross S. Bailie. 2007. "Measuring emotional and social wellbeing in Aboriginal and Torres Strait Islander populations: An analysis of a Negative Life Events Scale." International Journal for Equity in Health 6 (1), 1-12.

Lawson, Robert B., Jean E. Graham and Kristin M. Baker. 2007. A history of psychology: Globalization, ideas, and applications. Upper Saddle River: Pearson Prentice Hall.

Lehman, Darrin R., Chi-Yue Chiu and Mark Schaller. 2004. "Psychology and culture." Annual Review of Psychology Annual 55, 689-714.

Louw, Johann. 2002. "Psychology, history, and society." South African Journal of Psychology 32 (1), 1-8.

Lundy, Laura. 2007. "'Voice' is not enough: Conceptualising Article 12 of the United Nations Convention on the Rights of the Child." British Educational Research Journal 33 (6), 927-942.

Lynch, Philip. 2001. "Keeping them home: The best interests of Indigenous children and communities in Canada and Australia." Sydney Law Review 23 (4), 501-542.

Mendes, Philip, Bernadette J. Saunders and Susan Baidawi. 2016. Indigenous care leavers in Victoria. Melbourne: Social Inclusion and Social Policy Research Unit, Department of Social Work, Monash University.

Moore, Tim G., Ruth Beatson, Sophie Rushton, Rebecca Powers, Alana Deery, Noushin Arefadib and Sue West. 2016. Supporting the roadmap for reform: Evidence-informed practice. Prepared for the Victorian Department of Health and Human Services. 
Melbourne: Centre for Community Child Health, Murdoch Children's Research institute, The Royal Children's Hospital.

Negriff, Sonya, Janet U. Schneiderman and Penelope K. Trickett. 2015. "Child maltreatment and sexual risk behavior: Maltreatment types and gender differences." Journal of Developmental and Behavioral Pediatrics 36 (9), 708-716.

Nemeroff, Charles B. 2016. "Paradise lost: The neurobiological and clinical consequences of child abuse and neglect." Neuron 89 (5), 892-909.

Newton, Danielle, Andrew Day, Christine Gillies and Ephrem Fernandez. 2015. "A review of evidence-based evaluation of measures for assessing social and emotional wellbeing in Indigenous Australians." Australian Psychologist 50 (1), 40-50.

Noll, Jenny G. and Chad E. Shenk. 2013. "Teen birth rates in sexually abused and neglected females." Pediatrics 131 (4), e1181-e1187.

Norman, Rosana E., Munkhtsetseg Byambaa, Rumna De, Alexander Butchart, James Scott and Theo Vos. 2012. "The long-term health consequences of child physical abuse, emotional abuse, and neglect: A systematic review and meta-analysis." PLoS Medicine 9 (11), e1001349.

Ormhaug, Silije M., Tine K. Jensen, Tore Wentzel-Larsen and Stephen R. Shirk. 2014. "The therapeutic alliance in treatment of traumatized youths: Relation to outcome in a randomized clinical trial." Journal of Consulting and Clinical Psychology 82 (1), 52-64.

Pearce, Wendy M. and Cori Williams, C. 2013. "The cultural appropriateness and diagnostic usefulness of standardized language assessments for Indigenous Australian children." International Journal of Speech-Language Pathology 15 (4), 429-440.

Peña-Guzmán, David M. 2016. "What is psychology?" Foucault Studies 21, 200-213.

Perry, Bruce D. 2009. "Examining child maltreatment through a neurodevelopmental lens: Clinical applications of the neurosequential model of therapeutics." Journal of Loss and Trauma 14 (4), 240-255.

Piaget, Jean. 1978. "What is psychology?" American Psychologist 33 (7), 648-652.

Piaget, Jean, Paul Fraisse and Maurice Reuchlin. 2014. Experimental psychology its scope and method: Volume I (Psychology Revivals): History and method. London: Psychology Press.

Plener, Paul L., Anita Ignatius, Markus Huber-Lang and Joerg M. Fegert. 2017. "The consequences of child abuse, maltreatment and neglect on mental and somatic health in adulthood." Nervenheilkunde 36 (3), 161-167.

Prince, Martin, Vikram Patel, Shekhar Saxena, Mario Maj, Joanna Maselko, Michael R.

Phillips and Atif Rahman. 2007. "No health without mental health." Lancet 370 (9590), 859877.

Purdie, Nola, Pat Dudgeon and Roz Walker. 2010. Working together: Aboriginal and Torres Strait Islander mental health and wellbeing principles and practice. Canberra: Department of Health and Ageing.

Raman, Shanti, Sandra Reynolds and Rabia Khan. 2011. "Addressing the wellbeing of Aboriginal children in outofhome care: Are we there yet?" Journal of Paediatrics and Child Health 47 (11), 806-811.

Raman, Shanti, Sally Ruston, Scott P. Irwin, Phi Tran, Paul Rex Hotton and Sally Thorne. 2017. "Taking culture seriously: Can we improve the developmental health and wellbeing 
of Australian Aboriginal children in out-of-home care?" Child Care Health and Development 43 (6), 899-905.

Ranzijn, Robert, Keith McConnochie, K., Colleen Clarke and Wendy Nolan. 2007. "'Just another white-ology': Psychology as a case study." Counselling, Psychotherapy, and Health 3 (2), 21-34.

Rickwood, Debra, Pat Dudgeon and Heather Gridley. 2010. "A history of psychology in Aboriginal and Torres Strait Islander mental health." In Working together: Aboriginal and Torres Strait Islander mental health and wellbeing principles and practice, edited by Nola Purdie, Pat Dudgeon and Roz Walker, 13-24. Melbourne: Australian Institute of Health and Welfare.

Rust, John and Susan Golombok. 2014. Modern psychometrics: The science of psychological assessment. London and New York: Routledge.

Santoro, Ninetta, Jo-Anne Reid, Laurie Crawford and Lee Simpson. 2011. "Teaching Indigenous children: Listening to and learning from Indigenous teachers." Australian Journal of Teacher Education 36 (10), 65-76.

Skerrett, Delaney Michael, Mandy Gibson, Leilani Darwin, Suzie Lewis, Rahm Rallah and Diego De Leo. 2017. "Closing the gap in Aboriginal and Torres Strait Islander youth suicide: A social-emotional wellbeing service innovation project." Australian Psychologist 53 (1), 13-22.

Smith, Linda Tuhiwai. 2013. Decolonizing methodologies: Research and Indigenous peoples. London: Zed Books.

Stanley, Janet, Adam M. Tomison and Julian Pocock. 2003. Child abuse and neglect in Indigenous Australian communities. Melbourne: Australian Institute of Family Studies.

Stein, Mike. 2006. "Research review: Young people leaving care." Child \& Family Social Work 11 (3), 273-279.

Stoltenborgh, Marije, Marinus H. Van ljzendoorn, Eveline M. Euser and Marian J. Bakermans-Kranenburg. 2011. "A global perspective on child sexual abuse: Meta-analysis of prevalence around the world." Child Maltreatment 16 (2), 79-101.

Swenson, Cynthia Cupit, Cindy M. Schaeffer, Scott W. Henggeler, Richard Faldowski and Amy Marie Mayhew. 2010. "Multisystemic therapy for child abuse and neglect: A randomized effectiveness trial." Journal of Family Psychology 24 (4), 497-507.

Tilbury, Clare. 2009. "The overrepresentation of Indigenous children in the Australian child welfare system." International Journal of Social Welfare 18 (1), 57-64.

Timimi, Sami. 2014. "No more psychiatric labels: Why formal psychiatric diagnostic systems should be abolished." International Journal of Clinical and Health Psychology 14 (3), 208-215.

Triandis, Harry C., Roy S. Malpass and Andrew R. Davidson. 1973. "Psychology and culture." Annual Review of Psychology 24 (1), 355-378.

Tsey, Komia, David Patterson, Mary Whiteside, Leslie Baird and Bradley Baird. 2002. "Indigenous men taking their rightful place in society? A preliminary analysis of a participatory action research process with Yarrabah men's health group." Australian Journal of Rural Health 10 (6), 278-284.

Tufnell, Guinevere. 2005. "Eye movement desensitization and reprocessing in the treatment of pre-adolescent children with post-traumatic symptoms." Clinical Child Psychology and Psychiatry 10 (4), 587-600. 
Valentine, Bruce and Mel Gray. 2006. "Keeping them home: Aboriginal out-of-home care in Australia." Families in Society: The Journal of Contemporary Social Services 87 (4), 537-545.

Wilkie, Meredith. 1997. Bringing them home: Report of the national inquiry into the separation of Aboriginal and Torres Strait Islander children from their families. Sydney: Human Rights and Equal Opportunity Commission.

Williams, Shayne and lan Stewart. 1992. Community control and self-determination in Aboriginal education research: The changed roles, relationships and responsibilities of Aboriginal and non-Aboriginal researchers and Aboriginal communities. Paper presented at the National Aboriginal and Torres Strait Islander Higher Education Conference, Hervey Bay, Australia.

Wilson, Richard A. 2007. "Combining historical research and narrative inquiry to create chronicles and narratives." The Qualitative Report 12 (1), 20-39.

World Health Organization. 1992. The ICD-10 classification of mental and behavioural disorders: Clinical descriptions and diagnostic guidelines. Geneva: World Health Organization.

Zubrick, Stephen R., Christopher Holland, Kerrie Kelly, Tom Calma and Roz Walker. 2014. "The evolving policy context in mental health and wellbeing." In Working together: Aboriginal and Torres Strait Islander mental health and wellbeing principles and practice, edited by Pat Dudgeon, Helen Milroy and Roz Walker (Eds), 69-91. Canberra:

Commonwealth of Australia. 